\title{
CONTRIBUIÇÕES DA PEDAGOGIA CRÍTICA PARA A PESQUISA EM EDUCAÇÃO AMBIENTAL: UM DEBATE ENTRE SAVIANI, FREIRE E DUSSEL ${ }^{1}$
}

\author{
César Augusto Costa ${ }^{2}$ \\ Carlos Frederico Bernardo Loureiro ${ }^{3}$
}

Resumo: No presente trabalho recuperamos alguns dos conceitos fundamentais das obras dos educadores brasileiros Dermeval Saviani, Paulo Freire e do filósofo argentino Enrique Dussel, em suas interfaces e complementaridades, visando a contribuir com formulações teóricas oriundas do pensamento latino-americano para a Educação Ambiental crítica. Saviani, Freire e Dussel são indiscutíveis referências no campo da pedagogia crítica, com larga influência não somente na educação, mas também nos movimentos sociais, na teologia e filosofia da libertação e no pensamento social da América Latina. Reconhecemos que estes autores não são ambientalistas estritamente, mas suas visões de mundo e busca da emancipação humana e transformação social auxilia na práxis crítica educativa para a Educação Ambiental.

Palavras-chave: Educação Ambiental Crítica; Práxis Crítica Educativa; Pensamento Latino-Americano.

\footnotetext{
${ }^{1}$ Texto apresentado no VII Encontro de Pesquisa em Educação Ambiental (EPEA/2013) na cidade de Rio Claro/SP. Para esta nova versão foram inseridos pelos autores inúmeros acréscimos visando a ampliação e outros aprofundamentos.

2 Sociólogo. Doutor em Educação Ambiental/FURG. Pesquisador do Laboratório de Investigações em Educação, Ambiente e Sociedade (LIEAS-UFRJ). E-mail: csc193@hotmail.com

${ }^{3}$ Doutor em Serviço Social/UFRJ. Líder do Laboratório de Investigações em Educação, Ambiente e Sociedade (LIEAS-UFRJ). Professor do Programa de Pós-Graduação em Educação/UFRJ, do Programa de Ecologia Social/UFRJ e Programa de Pós-Graduação em Educação Ambiental/FURG.

Revbea, São Paulo, V. 10, N 1: 180-200, 2015.
} 


\section{Introdução}

O campo da Educação Ambiental(EA) no Brasil, desde a década de 2000, avançou na explicitação de suas divergências e convergências, que, em nosso entendimento, servem ao necessário processo de amadurecimento teórico-metodológico. As análises sobre seus referenciais teóricos mais utilizados dizem respeito à Educação Ambiental como prática social, visão de mundo e ação política no que se refere às relações sociedade-natureza (LOUREIRO; TREIN; TOZONI-REIS; NOVICK, 2009). Logo, explicam diferentemente as relações sociais através da história e, com isso, contribuem para diferentes formulações pedagógicas (TOZONI-REIS, 2007).

A Pedagogia crítica, origem, juntamente com 0 denominado socioambientalismo, da Educação Ambiental crítica, é uma síntese das propostas pedagógicas que têm como fundamento a crítica da sociedade capitalista e da educação como reprodutora das relações sociais injustas e desiguais (SAVIANI, 1987). Tais abordagens pedagógicas na Educação Ambiental podem são contextualizadas por Loureiro (2004, p.66-70), da seguinte forma:

No campo de abrangência da educação e suas abordagens, a influência de maior destaque encontra-se na pedagogia inaugurada por Paulo Freire, que se coloca no grupo das pedagogias libertárias e emancipatórias iniciadas nos anos de 1970 na América Latina, em seus diálogos com as tradições marxista e humanista. Esta se destaca pela concepção dialética de educação, que é vista como atividade social de aprimoramento pela aprendizagem e pelo agir, vinculadas aos processos de transformação societária, ruptura com a sociedade capitalista e formas alienadas e opressoras de vida. (...). Outra abordagem pedagógica importante é a históricosocial crítica, distinta em vários aspectos da anterior, mas que faz parte também da tradição emancipatória. É representada por Demerval Saviani, dentre outros. Contribui sobremaneira para o entendimento das políticas educacionais e da função social da educação.(...) Fica, portanto, o conselho para que cada leitor faça esta aproximação crítica, permitindo-se a necessária flexibilidade metodológica para se ir além do que já foi feito. Fica também destacada a proposição da primazia metodológica da dialética (marxiana, ou não), em suas diferentes formas de apropriação na educação por pensadores e/ou ativistas políticos, sem, contudo, deixar de criticá-la naquilo que se apresenta superado historicamente.

Isto vem assinalar que a prática educativa no Brasil se constituiu em diálogo com concepções pedagógicas críticas e pensadores inseridos numa perspectiva marxista ou em diálogo com esta (LOUREIRO; TREIN; TOZONIREIS; NOVICK, 2009), servindo, portanto, como importante parâmetro para 
diferenciações epistemológicas no campo educacional em geral, e em particular na EA.

A reflexão que nos propusemos fazer nesse texto visa tratar de contribuições teóricas a partir de três grandes referências do campo crítico do pensamento educacional e político latino-americano: Dermeval Saviani, Enrique Dussel e Paulo Freire, apontando convergências à luz da Educação Ambiental crítica. Cabe recordar que para esta perspectiva epistêmica-política, os problemas ambientais são determinados socialmente e situados historicamente, não sendo possível superá-los sem o enfrentamento e transformação do conjunto de relações humanas e sociais que nos constituem como seres sociais naturais (LOUREIRO, 2012; 2009; LUKÁCS, 1979). Portanto, a contribuição de autores como os selecionados, mesmo que não sendo nenhum deles estritamente inseridos no debate ambiental, é fundamental para os processos educativos que visam à superação das relações de dominação e expropriação intrínsecas ao capitalismo, fundamento da intensificação da exploração e destruição da natureza (HARVEY, 1996). Compreendemos que a educação, na perspectiva pedagógica crítica, busca contribuir para a compreensão da realidade que abrange a "representação da coisa" (aparência/fenômeno) e a "coisa em si" (essência/conceito) para a transformação societária e da educação, no processo de formação humana (MÉSZÁROS, 2005). Torna-se evidente que:

\begin{abstract}
Nesta concepção de educação, a abordagem dos conteúdos programáticos ou dos conhecimentos a serem construídos requer considerarmos, como importante recurso pedagógico, a realidade vivenciada por educadores e educandos em seus locais de estudo, moradia e trabalho, destacando-se a diversidade cultural e a exclusão social que caracterizam a sociedade. Esta pedagogia fundamenta-se no entendimento de que as relações sociais de dominação e de exploração capitalistas são internalizadas, como ideologia dominante que informa uma leitura/postura diante do cotidiano, e materializamse nos problemas sociais e ambientais (LOUREIRO; TREIN, TOZONI-REIS, NOVICK, 2009, p 89).
\end{abstract}

Tais autores são ícones do pensamento filosófico, revolucionário e pedagógico latino-americano, a partir dos quais temos a intenção de identificar algumas categorias teóricas neste complexo mapa da realidade latinoamericana, que auxiliam a refletir as práticas educativas ambientais. Esse movimento de aproximação é relevante para a pesquisa em educação ambiental, uma vez que temos uma grande quantidade de pesquisas em vários programas de pós-graduação que não abdicam do trabalho de procurar os elos que unem os povos a partir de uma história comum e do movimento de superação das relações sociais alienadas no capitalismo como condição para a materialização de novas relações sociais com/na natureza. 
Por outro lado, as convergências teóricas trazidas neste trabalho não buscam enquadrar as reflexões em esquemas fechados e, por isso, limitadores da riqueza do pensamento produzido com o passar dos anos. Tão somente,

entendemos que, por ser herdeira de uma determinada formação histórica e cultural, forjou-se nesta parte do mundo um pensamento com algumas características próprias, em princípio, nem melhor nem pior que o pensamento em outros lugares. Mas é um pensamento que, em meio à fugacidade das ideias de fora, que como ondas, se sucedem em modas, busca encontrar raízes por onde continua subindo a seiva que, mesmo imperceptível, continua alimentando práticas e esperanças (STRECK; ADAMS; MORETTI, 2010, p.20).

O nosso ponto de partida para refletirmos suas implicações na Educação Ambiental crítica é de que nossas sociedades de classe estão em dívida com enormes parcelas da população condenadas a viverem em estados de "sub-emancipação". No mesmo sentido, várias práticas educativas ambientais ou pesquisas sobre o tema, supostamente voltadas para emancipação, não estão inseridas numa trajetória de lutas sociais, que foram ignoradas, silenciadas ou esquecidas em nossa caminhada pedagógica. Constata-se que parte dos educadores e pesquisadores não se preocupa com a tarefa social da ciência num país de tantas exclusões, isto é, não dialetizam porque as políticas públicas obedecem mais a ética do mercado do que objetivam um compromisso efetivo com o direito das pessoas, de modo a dar condições à dignidade humana (ANDREOLA, 2003).

Disso decorre a indagação: seria possível enxergar o pensamento pedagógico latino-americano desde outra lógica, a partir dos condenados da terra ${ }^{4}$ ? (FANON, 1979). Indicamos em nosso ensaio, que este desafio:

Trata-se de buscar condições para a superação da colonialidade pedagógica impregnada na América Latina e sua história colonial de mais de quatro séculos. Com a chegada dos europeus foram subordinados as histórias e as cosmologias dos povos que aqui habitavam. A colonialidade pedagógica

\footnotetext{
${ }^{4}$ A obra Os Condenados da Terra, de Frantz Fanon, livro considerado, junto com Pedagogia do Oprimido, de Paulo Freire, um dos clássicos mais importantes da descolonização. Fanon é compreendido no contexto em que a população argelina obriga-se a combater o poderoso Estado Colonial Francês. Aqui, o povo, anteriormente sob o jugo da colonização, buscava afirmar seu protagonismo nas metamorfoses históricas, banindo preconceitos que afirmavam categoricamente a África como continente sem pensamento autônomo e sem história. Ao concluir a reflexão em sua obra, com voz profética, Fanon (1979, p. 271-74) anuncia a esperança: "o dia novo que já desponta deve encontrar-nos firmes, avisados e resolutos (...). Deixemos a Europa que não cessa de falar do homem enquanto o massacra por toda parte (...), em todas as esquinas de suas próprias ruas, em todas as esquinas do mundo", uma Europa que assumiu a direção do mundo com "ardor, cinismo e violência", obrigando-se a manter "um diálogo consigo mesma, um narcisismo cada vez mais obsceno". O caráter educativo da obra de Fanon, aparece na proposta da luta organizada e solidária (...) (GHIGGI E KAVAYA, 2010, p. 378-380).
}

Revbea, São Paulo, V. 10, Nº 1: 180-200, 2015.

revista brasileira educação ambiental 
sinaliza o sentimento de inferioridade, com todas as ausências que se produzem nos relatos da modernidade como resultado de uma construção europeia de história, aqui realizada, a favor dos interesses de Europa (STRECK, ADAMS, MORETTI, 2010, p. 22).

A lógica colonial, se expressa pela distribuição desigual da riqueza, uso intensivo de recursos naturais e pelo domínio da epistemologia, radicalizados desde o estabelecimento do sistema de classificação hierárquica em todas as esferas sociais até a supressão de economias e culturas existentes antes da chegada dos colonizadores (DUSSEL, 2000). Negar as origens das civilizações estabelecidas antes da colonização atravessa a história da América Latina. Os colonizados, por sua vez, como forma de resistência, aprenderam a cultura dos dominadores, tanto no campo da atividade material quanto da prática religiosa que engendrava uma subjetividade colonizada. Dentro desta perspectiva, colonialidade e independências colocam-se de forma contraditória e dinâmica na luta dos povos indígenas e afrodescendentes pela emancipação política (STRECK, ADAMS, MORETTI, 2010), o que segundo Porto-Gonçalves(2012, p.16):

Essa tradição tem na geopolítica atual o desenvolvimento sustentável como nova forma de colonização/exploração. Com/contra ela, criativamente, corresponde uma série de respostas críticas com o novo protagonismo, a partir das lutas locais/regionais de camponeses, de povos indígenas e de afroamericanos que, no novo contexto geopolítico que se abre pós anos 1960, passam a ter condições de se expressar à escala internacional, inclusive se apropriando dos vetores ecológico e tecnológico. (...). Surge um novo léxico teóricopolítico em que se fala de descolonização, de interculturalidade, de transmodernidade; de pluralismo jurídico, que respeite os direitos das gentes, consuetudinários, não mais somente o direito fundado nos princípios liberais do indivíduo e da propriedade privada;

Para desenvolver uma pedagogia emancipatória com características dos nossos povos, é preciso partir do encontro contraditório, porém indissociável entre cultura europeia, indígena e africana. A primeira identificada com o projeto da modernidade burguesa, branca e capitalista, e as outras duas que carregam até hoje as conseqüências em termos de subalternidade e resistência: a colonialidade. Dito isto,

Acreditamos que a atitude adequada não seja negar o legado da modernidade, mas reconhecê-lo e contextualizá-lo histórica e epistemologicamente, contudo, a lógica da monocultura eurocêntrica e abrir caminhos para outros paradigmas. Superar a colonialidade significa deixar de ser apêndice das 
transformações e assumir igualmente o protagonismo da construção de sociedades que valorizem as características da diversidade dos nossos povos (STRECK; ADAMS; MORETTI, 2010, p. 24).

Levando em conta os aspectos acima, compartilhamos da necessidade de uma visão pedagógica a partir de Dermeval Saviani, Enrique Dussel e Paulo Freire frente à questão da exclusão e suas implicações para 0 debate ambiental, uma vez que a colonialidade sob o modo de produção capitalista impede, em termos freireanos, o ser humano de ser-mais.

Sendo assim, temos clareza teórica que tais autores não se dedicaram especificamente ao estudo da educação ambiental, mas suas amplas reflexões abrem possibilidades para refletirmos as relações sociedade-natureza a partir de suas teorias do conhecimento e de seus métodos pedagógico.

\section{Por que Dermeval Saviani, Enrique Dussel e Paulo Freire?}

Saviani constitui uma referência para o entendimento da pedagogia crítica no Brasil auxiliando de modo ímpar nas formulações ao campo da pedagogia crítica para a EA. Sua Pedagogia Histórico-Crítica não é uma proposta educativa formulado somente por ele, mas por um conjunto de pesquisadores que, desde fins da década 70 e começo da década de 80, dialogam acerca da realidade brasileira. Identificamos um marco de sua formulação nas reflexões de Saviani sobre as diferentes teorias educativas em sua obra Escola e Democracia (1987) onde aponta duas teorias educacionais: uma reprodutivista e a outra, crítico-transformadora. $\mathrm{O}$ autor se coloca a favor de uma teoria crítica que, compreendida em seu caráter histórico, oferece respostas à questão que ele considera central: "é possível encarar a escola como uma realidade histórica, isto é, suscetível de ser transformada intencionalmente pela ação humana?' (SAVIANI, 1987, p. 35).

A relevância das reflexões de Dussel para a Educação Ambiental crítica à luz do debate sobre a exclusão consiste no fato do autor considerar o sofrimento do outro como consequência de uma realidade em que sujeitos subjugam outros (entendidos como inumanos, inferiores, não civilizados, por meio de relações desiguais e opressivas de poder). A partir disso, analisa criticamente o discurso eurocêntrico moderno e a possibilidade de superação do irracionalismo moderno por meio da razão crítico-libertadora. Dussel está para além de uma mera reflexão racional de constatação da negação do sujeito humano uma vez que sua teoria se constitui em uma ética crítica, ou seja, "da transformação como possibilidade da reprodução da vida da vítima e como desenvolvimento factível da vida humana em geral" (DUSSEL, 2000, p. 564). Nisso consiste o postulado essencial fundamental da sua Filosofia da Libertação como veremos à luz do debate.

A opção por Paulo Freire justifica-se, não por ser autor mais citado no campo da Educação Ambiental no Brasil, mas porque podemos assim, Revbea, São Paulo, V. 10, Nº 1: 180-200, 2015.

revista brasileira educação ambiental 
encontrar em sua obra os pressupostos teóricos para subsidiar a educação ambiental, pois o pensamento de Freire tem muito a contribuir e a propor ações aos que se preocupam com uma Educação Ambiental crítica vista na sua totalidade (TOZONI-REIS, 2006).

\title{
A perspectiva político-pedagógica em Saviani, Freire e Dussel para a EA
}

Convém neste momento da discussão, apontar as perspectivas político-pedagógicas de Dermeval Saviani, Paulo Freire e Enrique Dussel, mas antes de tudo, explicitando seus principais postulados.

\begin{abstract}
Consideremos, primeiramente, a importância de explicitar, na prática educativa ambiental, as abordagens teóricometodológicas que fundamentam nossas ações para realizá-las mais conseqüentes e coerentes, o que significa compreender seus conteúdos filosófico-políticos e teórico-metodológicos. Assim, a Educação Ambiental crítica, transformadora e emancipatória emerge da pedagogia crítica, que tem seu ponto de partida na teoria crítica de interpretação da realidade social (LOUREIRO; TREIN; TOZONI-REIS, NOVICK, 2009, p. 85-6).
\end{abstract}

Na década de 1980, a chamada pedagogia histórico-crítica formulada por Saviani, começou a ocupar espaço no campo crítico. Exercendo influência entre os educadores brasileiros, procura deslocar a questão dos métodos de aquisição de conhecimentos destacando a importância da apropriação dos conteúdos e conhecimentos vistos como patrimônio da humanidade por parte das classes dominadas, como instrumento essencial para superar as relações de subordinação e expropriação (LOUREIRO, 2006). Para esta concepção, a carência de entendimento da dialética "indivíduo, grupos sociais e sociedade", ou seja, da constituição entre estas dimensões, faz com que se ignore o contexto não dando ênfase às mediações do professor e sua relevância na formação da cidadania. Nesta abordagem, o professor recebe maior atenção cabendo a ele, não somente sensibilizar o aluno, mas levá-lo a uma compreensão das múltiplas relações sociais que formam a realidade da qual está inserido.

Os pressupostos filosófico-políticos da Pedagogia Histórico-Crítica de Dermeval Saviani, base da educação crítica estão relacionadas com sua posição política que diz respeito à compreensão das relações sociais historicamente estabelecidas pelos sujeitos na sociedade (TOZONI-REIS, 2007). Para ele, a educação na sociedade moderna e capitalista é contribuir para um movimento de transformação desta sociedade para mais justa e igualitária. Se a transformação da sociedade é fim político da educação, Saviani (1987, p. 68-9) indica que seu papel, neste processo, é contribuir nesta transformação assumindo que: 
A pedagogia revolucionária é crítica. E, por ser crítica, sabe-se condicionada. Longe de entender a educação como determinante principal das transformações sociais, reconhece ser ele elemento secundário determinado. Entretanto, longe de pensar, como faz a concepção crítico-reprodutivista, que a educação é determinada unidirecionalmente pela estrutura social dissolvendo-se a sua especificidade, entende que a educação se relaciona dialeticamente com a sociedade. Nesse sentido, ainda que elemento determinado, não deixa de influenciar o elemento determinante. Ainda que secundário, nem por isso deixa de ser instrumento importante e por vezes decisivo no processo de transformação da sociedade.

Encontramos nas elaborações de Saviani, o pensamento materialista histórico-dialético como referencial teórico que dá maior sustentação a suas análises da realidade social. Saviani (1996) alude sobre a relevância deste referencial no processo de superação do senso comum educacional (conhecimento da realidade imediata, aparente, da educação), pois permite, pela reflexão teórica (movimento do pensamento, reflexões, abstrações acerca dos fenômenos educacionais e educativos), alcançar a "consciência filosófica" que consiste na compreensão aprofundada da realidade, definida como "realidade concreta da educação" - concreta pensada - realidade educacional plenamente compreendida. " $A$ contribuição da educação para a transformação social, na pedagogia histórico-crítica, portanto, é criar condições objetivas, sistematizadas, de apropriação crítica, pelos educandos, dos conteúdos culturais significativos e ressignificados como instrumentos de construção de uma prática social transformadora" (TOZONI-REIS, 2007, p. 213).

Sendo assim, a educação é vista como mediação da prática social. Tal prática social se põe como ponto de partida e ponto de chegada da prática educativa. Ou seja, um método pedagógico que parte da prática social onde professor e aluno se encontram inseridos na compreensão e enfrentamento dos problemas colocados pela prática social. Gramsci (2001) enfatiza que o reaprender a aprender sobre a prática social requer uma troca constante entre teoria e prática, no reconhecimento sobre a alienação e o domínio do produto histórico de nossa ação. Trata-se de uma transformação radical, revolucionária: uma nova proposta a todas as esferas do saber/fazer humanos.

Assim para Saviani:

[...] a teoria que está empenhada em articular a teoria e a prática, unificando-as na práxis. É um movimento prioritariamente prático, mas que se fundamenta teoricamente, alimenta-se da teoria para esclarecer o sentido, para dar direção à prática. Então, a prática tem primado sobre a teoria, na medida em que é originante. A teoria é derivada. Isto significa que a prática é, ao mesmo tempo, fundamento, critério de verdade e finalidade da teoria. A prática, para desenvolverse e produzir suas conseqüências, necessita da teoria e precisa ser por ela iluminada (2005, p. 141-142).

Revbea, São Paulo, V. 10, N 1: 180-200, 2015.

revista brasileira

educação

ambiental 
Constatamos a relevância da teoria para se pensar os problemas da realidade. É necessário refletir sobre os problemas de sua prática educativa, entendendo-os como determinações das contradições do seu tempo histórico, síntese de múltiplas determinações. É nesse contexto que a práxis educativa coloca a prática como ponto de partida e ponto de chegada do processo educativo (SAVIANI, 2005). Significa dizer que no processo pedagógico, ao pensar sobre sua prática, precisa de um processo de análise, sendo que esta, por sua vez, pressupõe um método (enquanto teoria, e não apenas enquanto forma) para se pensar a realidade (TEIXEIRA; TOZONI-REIS, TALAMONI, 2011).

Levando em conta tais pressupostos pedagógicos, Saviani oferece elementos essenciais para a elaboração de uma Pedagogia histórico-crítica como proposta de apropriação crítica de saberes para a EA. A pedagogia crítica na EA articula a educação como processo de formação humana omnilateral com a concepção de ambiente pautado nos aspectos sociais, históricos e políticos, compreendido como concreto pensado, como "síntese de múltiplas determinações".

No que tange suas relações com a EA, é, portanto, um espaço de formação humana e de apropriação pelos sujeitos em seus processos de conhecer o mundo e estar no mundo ativamente transformando-o. Logo, o processo educativo ambiental neste horizonte relaciona sociedade e ambiente às formas históricas com que o homem se relaciona com o ambiente assim e também entre si, priorizando a necessidade da participação política dos sujeitos. Participação política como resultado da apropriação crítica e reflexiva de conhecimentos (SAVIANI, 2005a). Ou seja, esse é o ponto central e desafiante para aqueles que estão comprometidos com a Educação Ambiental crítica na perspectiva defendida por Saviani. Tal desafio exige um pensamento reflexivo-dialético-ação-reflexão-ação- sobre a prática social, em um contexto onde a educação é entendida como mediação no seio da prática social global (SAVIANI, 2005).

Para Freire, um dos seus postulados centrais está na relação opressoroprimido, e, no caso de Dussel, a antinomia alienação- libertação frente à educação ambiental. No entendimento de Dussel:

Até muito recentemente a política não tinha descoberto sua responsabilidade ecológica [...] A previsão de permanência da vida da população de cada nação na humanidade que habita o planeta Terra é primeira e essencial função da política [...] Uma humanidade extinta obviamente aniquilaria o campo político e todos seus sistemas possíveis (2007, p.64).

Sendo assim, consideramos que a abordagem ambiental na América Latina não é algo recente (PORTO-GONÇALVES, 2012), embora neste debate, ainda careça de sistematizações maiores, bem como de uma crítica mais consistente dos seus problemas. Uma abordagem da questão ambiental a partir da América Latina não pode ignorar o contexto em que se dá a 
institucionalização dessa problemática no período que se abre desde os anos 1970, havendo uma contribuição específica na região a esse debate teóricopolítico. Nesse contexto, a grande contribuição latino americana está na crítica à sociedade capitalista (consumismo/produtivismo), fortemente ancorada em categorias marxistas, acompanhada pela afirmação e pelo respeito aos povos originários e tradicionais, ao aprendizado com seus costumes, culturas e modos de produção, e à necessidade de diálogo de saberes.

Segundo Porto-Gonçalves (2012, p. 26-27):

Muito embora correntes hegemônicas da esquerda marxista tivessem, de início, criticado o ecologismo, o fato é que diferentes movimentos sociais, sobretudo na América Latina, começaram a assimilar a questão ambiental à sua agenda política. Junto com esses movimentos se desenvolveram importantes correntes teórico-políticas no campo ambiental: a "ecologia popular", o "ecologismo dos pobres" e o ecosocialismo - onde se destacaram intelectuais como o líder seringueiro Chico Mendes, assim como o epistemólogo mexicano Enrique Leff, o economista catalão Joan Martinez Alier que tem fortes ligações com movimentos sociais latinoamericanos, o antropólogo colombiano Arturo Escobar, o biólogo e antropólogo mexicano Victor Toledo, o sociólogo marxista brasileiro Michel Löwy, entre tantos. Essa contribuição teórica-política é tão importante para compreender os complexos processos sócio-históricos que estão curso como são, ainda hoje, as teses de José Carlos Mariátegui elaboradas nos anos vinte do século passado, a Teoria da Dependência, sobretudo em sua vertente marxista (Rui Mauro Marini e Theotonio dos Santos), a Pedagogia do Oprimido (Paulo Freire), a Teologia da Libertação (Frei Beto, Leonardo Boff, Enrique Dussel), assim como o Pensamento Descolonial (desde Franz Fanon e Aimé Cesaire, ambos caribenhos, até o mexicano Pablo González Casanova, a aymara-boliviana Silvia Rivera Cusicanqui e o peruano Aníbal Quijano).

$\mathrm{Na}$ perspectiva de Freire, constata-se que este cenário capitalista e colonial determina a situação de opressão desumaniza, assim os oprimidos não podem ser livremente porque são negados em suas dimensões fundamentais e constitutivas. Torna-se evidente que em suas práticas políticas e pedagógicas, no método proposto pelo autor, os oprimidos vão buscar se libertar lutando contra quem os desumaniza. Mas a luta pela libertação deve ser a luta pela recuperação da humanidade. Segundo Freire: "a grande tarefa humanista e histórica dos oprimidos é a de libertar-se a si e aos opressores" (1983, p. 31). "A pedagogia do oprimido, nas trilhas da teoria da dependência, se fundamenta na visão da América Latina como lugar dependente, mas também de possibilidades" (STRECK, 2010, p.330). A superação desta situação dependente será possível mediante uma dupla ruptura: externa, trazendo para a sociedade o centro das decisões; e interna, superando a 
sociedade cindida pelas classes. O alcance teórico e importância da obra de Paulo Freire podem ser vistos neste sentido:

Paulo Freire representa um momento de consolidação de um pensamento pedagógico latino-americano. Suas obras constituem o núcleo de um movimento educativo que na segunda metade do século XX passou a ser conhecido como Educação Popular (...). Trata-se de um momento de ruptura que é também um momento de libertação da pedagogia. Os teólogos haviam defendido a tese de que a teologia da libertação implica a libertação da teologia, no sentido de que ela vai muito além do ensino de conteúdos, mas se refere ao próprio processo de fazer teologia; para um grupo de filósofos, não poderia haver filosofia da libertação sem a libertação da filosofia. Em Freire temos um exercício de libertação da pedagogia. Em primeiro lugar, ela se torna uma pedagogia do outro, do oprimido (STRECK, 2010, p. 331).

Também os horizontes teóricos da Filosofia da Libertação de Enrique Dussel podem assim ser aclarados:

a experiência inicial da Filosofia da Libertação consiste em descobrir o "fato" opressivo da dominação, em que sujeitos se constituem "senhores" de outros sujeitos, no plano mundial (desde o início da expansão europeia em 1492; fato constitutivo que deu origem à "Modernidade"), Centro-Periferia; no plano nacional (elites-massas, burguesia nacional-classe operária e povo); no plano erótico (homem-mulher); no plano pedagógico (cultura imperial, elitista, versus cultura periférica, popular, etc.); no plano religioso (o fetichismo em todos os níveis), etc. (DUSSEL, 1995, p. 18) (...). Por meio de sua Filosofia da Libertação analisa o processo opressivo da dominação, em que uns se tornam senhores de outros no plano mundial, questionando o discurso da modernidade. Tanto a sua filosofia quanto a sua Ética da Libertação possuem clara opção política pelas vítimas do sistema-mundo, compreendido como o processo de ampliação da influência cultural de um sistema inter-regional (alta cultura ou sistema civilizatório) a outras culturas. (OLIVEIRA; DIAS, 2012, p.92).

O desafio para os oprimidos é de realizarem uma libertação que evite uma simples inversão dos pólos da situação opressora. Sendo assim, faz-se necessária a superação da própria contradição opressor-oprimido que acontece, segundo Freire, na luta dos oprimidos pela sua libertação: "Os opressores, violentando e proibindo que os outros não sejam igualmente ser; os oprimidos, lutando por ser, ao retirar-Ihes o pode de oprimir e de esmagar, Ihes restauram a humanidade de que haviam perdido no uso da opressão" (1983, p. 46). Logo, as tentativas de libertação que venham dos opressores jamais passarão de falsa generosidade, uma vez que, sua "suposta 
generosidade" implica na permanência da injustiça e na existência da pobreza diante à situação de necessidade. Entendemos que a verdadeira generosidade incide na luta pela restauração da plena humanidade na situação dos oprimidos e na superação destas "generosidades desiguais" (BOUFLEUER, 1991).

A concepção política de Freire é o que dá sentido à utopia de construção da nova sociedade livre, solidária e humanista. Tal projeto impele uma pedagogia da luta política a ser elaborada no processo da luta libertadora que os oprimidos tratam historicamente. Por essa razão que não deve existir receitas prontas e previsões de como acontecerá o processo político libertador, porém, existe a exigência radial do cultivo da dialogicidade para que possamos superar as práticas que reproduzem a opressão por uma nova cultura essencialmente humanizadora (ZITKOSKI, 2007). Além de uma política pedagógica dos oprimidos, a união dos diferentes, que não se confunde com os postos desigualmente na sociedade, é exigida na luta contra os antagonismos de classe (FREIRE, 1995). Essa estratégia é fundamental na luta política de libertação no que se refere à supressão das classes, às relações de gênero, aos preconceitos étnicos e à desigualdade social reproduzida pela questão ambiental. Ou seja, o que está em jogo é a permanente luta de classes historicamente determinada:

O que acontece é que luta é uma categoria histórica e social. Tem, portanto, historicidade. Muda de tempo-espaço. A luta não nega a possibilidade de acordos, de acertos entre as partes antagônicas (...). Há momentos históricos em que a sobrevivência do todo social, que interessa às classes sociais, Ihes coloca a necessidade de se entenderem, o que não significa estarmos vivendo um novo tempo, vazio de classes e conflitos (FREIRE, 1994, p. 43).

Aqui se faz necessário, trazermos a contribuição dusseliana ao sentido e significado do termo libertação. Segundo Dussel (DUSSEL, 1986), a filosofia latino-americana terá sua originalidade ao se fundar sobre um projeto éticoantropológico interpretante do homem latino-americano. Tal projeto só poderá ser realizado se constituir-se numa filosofia sobre novas bases metodológicas e históricas, sendo necessário ultrapassar os modelos metodológicos das filosofias européias que geram a alienação dos latino-americanos (OLIVEIRA, s/d). No plano metodológico, Dussel, partindo de Marx e da tradição semita, propõe uma nova formulação metodológica: o Método anadialético. Trata-se de uma metodologia filosófica original, porque se distingue e supera os procedimentos e categorias etnocêntricas da modernidade européia. O Método da Filosofia da Libertação terá seu ponto de partida no princípio da alteridade, onde o pressuposto desse método estabelece que o discurso filosófico possui um caráter eminentemente ético, para além da dimensão puramente lógica. $O$ discurso é válido ou inválido não pôr sua correção lógica, mas por seu acordo ou desacordo com a justiça (DUSSEL, 1986).

Para Dussel, a alienação consiste no fato de tomar o "outro enquanto instrumento" (objeto prático), isto é, enquanto um ser que serve de mediação 
para a realização das vontades do outro, aniquilando a semelhança e a distinção. Assim, a alienação resulta de uma práxis de dominação, que é a afirmação de um projeto totalizador opressor e autoritário. Nessa perspectiva, o projeto dominante impõe seu horizonte de abrangência, utilizando e instrumentalizando a tudo e a todos em função de uma cultura individualista, intrínseca ao capitalismo. Para assegurar a realização desse projeto dominador seus interessados promovem diversos tipos de alienação: do trabalho, da cultura, a política, a religiosa, a educativa (DUSSEL 1977).

A libertação dentro deste horizonte consiste na desalienação das pessoas, povos, culturas e instauração de uma nova ordem fundada no respeito à alteridade e exterioridade humana, pois no processo de desalienação é preciso estar atento para não compreender o outro apenas como dimensão objetiva do mundo, como um meio para realizar determinado "projeto libertador". O ethos, o caráter da libertação exige não repetir a mesma ordem dominante e excludente, mas criar uma nova a serviço do outro. Esse ethos, para Dussel, se estrutura a partir do acolhimento alterativo, amor de justiça, acolhimento do outro enquanto outro que nos leva a compartilhar de sua miséria, da miséria de um povo, dos sofrimentos dos excluídos, dos explorados. A partir daí, somos provocados a buscar relações fraternas e solidárias que nos motiva à subversão do sistema para reconstruí-lo numa justiça real que afirma a dignidade humana.

Nesta perspectiva, o método de Dussel, tem como ponto de partida uma opção ética e uma práxis histórica concreta. Alia o rigor teórico e a ação ético-política à favor da libertação humana, uma vez que, a indiferença compactua com o sistema vigente. Ou seja, para Dussel é através da Ética da Libertação com seus princípios que traz em seu horizonte uma ética necessária em face da "miséria que aniquila a maioria da humanidade no final do século XX", junto com a destruição ecológica (DUSSEL, 2000, p. 15).

Sua ética fundamenta-se também na criticidade que entendemos ser vital para a perspectiva ambiental assumida nesta pesquisa. Significa que sua razão crítica "permite o (auto) reconhecimento das vítimas do sistema-mundo (dominados: operários, índios, escravos, etc. e discriminados: mulheres, idosos, incapacitados, imigrantes, etc.), bem como o descobrimento de suas alteridades e autonomias, negadas pelo sistema-mundo vigente" (OLIVEIRA e DIAS, 2012, p. 98).

Enrique Dussel alude a um ethos da libertação que pressupõe algumas características que marcam a liderança libertadora. Para Dussel, ethos significa costume ou o caráter de uma pessoa ou de um povo. Na perspectiva libertadora, consiste no modo de deixar que o outro seja Outro, em reconhecêlo como projeto novo. Mas, como o Outro só se revela pela palavra, torna-se necessária a necessidade escutar sua voz que transcende o além do meu mundo.

Postulamos que a proposta de Dussel se aproxima de Freire em 
"doação" do saber revolucionário ao oprimido e indica uma postura de confiança e de diálogo, ele está assinalando que o projeto de libertação deve se construído com o oprimido. Da mesma forma, há uma complementaridade entre quem cala e diz sua palavra e aquele que escuta e atende, tal como propõe Dussel. O decisivo para ambos os autores, é considerar o oprimido como pessoa digna de respeito e dedicação, capaz de ter uma posição contribuindo para sua libertação (BOUFLEUER, 1991, p.117).

Partindo das convergências nestes autores, iremos tecer algumas contribuições à Educação Ambiental crítica. Esta considera de modo integrado as relações sociais e ecológicas. Sendo assim, suas bases éticas e antropológicas colaboram e cimentam a negação da opressão como "naturalização das relações" (PERALTA; RUIZ, 2004). É o contexto social e econômico que determina as formas de expropriação e dominação, sendo possível transformá-lo, mas com a condição de que cada sujeito e grupo social se transformem em sujeitos históricos conscientes de sua real condição de alienação no marco de uma sociedade desigual e constituída, portanto, em classes.

As propostas de Paulo Freire e Enrique Dussel para a Educação Ambiental crítica auxiliam na adoção de estratégias políticas dirigidas à emancipação/libertação inscritas nos marcos de um processo de radicalização da questão social, sendo contrários à lógica neoliberal e desenvolvimentista hegemônicas, próprias da feição que o capitalismo assume na América Latina em sua matriz colonial.

A reflexão de Dermeval Saviani e sua Pedagogia Histórico-Critica ao qual também nos tópicos anteriores buscamos referencial teórico e metodológico, possui pertinência para as nossas reflexões em Educação Ambiental crítica. Tal referencial é construído coletivamente por autores que se dedicam, ao estudo das contribuições do pensamento marxista para a educação. "Para a Pedagogia Histórico-Crítica qualquer aspecto do processo educativo exige a definição da função social da educação escolar. Isto é, os objetivos, valores e princípios educativos respondem a um determinado projeto de formação humana, a um modelo de sociedade que se pretende garantir/reproduzir - ou superar/transformar" (TOZONI-REIS et al., 2013, p.7).

Assim, a educação deve superar o conhecimento imerso na cotidianidade, o senso comum e a compreensão sincrética da realidade pela assimilação da cultura erudita, da compreensão da totalidade e da essência que é intrínseca aos fenômenos, como indica Saviani (1987).

A Pedagogia Histórico-Crítica radicaliza a ideia de que a educação escolar consiste na apropriação dos conteúdos escolares, partindo da prática social em que professor e aluno estão inseridos, consolidando-se num processo que permite ao aluno tomar posse dos "instrumentos teóricos e práticos necessários ao equacionamento dos problemas detectados na prática social' (SAVIANI, 1987) que possibilitam às camadas populares lutarem pela superação das condições de opressão em que vivem. Teorizando a Pedagogia

revista brasileira educação ambiental 
Histórico-Crítica de Saviani, argumentamos que a educação é um trabalho imaterial, que produz no sujeito singular a humanidade produzida historicamente e coletivamente na sociedade. Assim, seu objeto identificar os elementos culturais necessários a serem assimilados pelos indivíduos para que estes se tornem humanos desenvolvendo maneiras mais adequadas para que essa apropriação cultural seja possível (TOZONI-REIS et al., 2013a).

Como defende a Pedagogia Histórico-Crítica, apontamos que a mesma propiciar às classes populares a conquista e apropriação do saber sistematizado, socializar progressivamente o conhecimento científico, convertendo-o num instrumento de emancipação, exercendo assim um papel ativo na construção da realidade social (SAVIANI, 2010).

Colocando, portanto, a necessidade de transformar as relações sociais de dominação como ponto central da sustentabilidade ambiental que busca a educação ambiental, consideramos a crise socioambiental atrelada à desigualdade de classes e das diferenças econômicas que, por sua vez, levam à desigualdade de aptidões e faculdades da natureza humana. Se negarmos aos indivíduos a educação, em seu sentido mais pleno, estaremos negando a possibilidade das pessoas serem "mais humanas", no sentido marxista dessa expressão (TOZONIREIS et al., 2013b, p.72).

A contribuição de Paulo Freire põe em evidência os fundamentos filosófico-políticos na sua teoria do conhecimento e ação no mundo que denominamos educação libertadora. Uma das principais concepções da educação libertadora é que a educação é uma atividade em que os sujeitos, educadores e educandos, mediatizados pelo mundo educam-se em comunhão (TOZONI-REIS, 2006). Esse processo, Freire chama de "conscientização", isto é, ao se aprofundarem no conhecimento da realidade vivida, real $e$ concretamente pelos sujeitos, os quais têm as possibilidades de emergir no conhecimento de sua própria condição, ou seja, de sua própria vida. Em vista disso, a educação libertadora é uma alternativa política à educação tradicional, que denominou "educação bancária". A educação libertadora objetiva questionar as relações dos homens entre si e deles com o mundo, criando condições para um processo de desvelamento do mundo que tem como prioridade transformá-lo socialmente. Para Freire, a educação não é a garantia das transformações sociais, mas as transformações são impossíveis sem ela, sem uma visão crítica da realidade (FREIRE, 1983).

A Pedagogia do Oprimido de Freire tem seu projeto histórico-político, pertencente à humanidade, dada a sua universalização. Dessa forma, a Pedagogia do Oprimido, é um projeto coletivo que se assumido com liberdade e criatividade visa um projeto de emancipação. Este processo histórico de transformação e libertação é desenvolvido no diálogo e no fazer conjunto com os sujeitos históricos, a multidão dos oprimidos, que constituem a "comunidade das vítimas" segundo Dussel (2000), dos "oprimidos", segundo Freire. Vislumbra-se aí, um projeto pedagógico de libertação, uma práxis Revbea, São Paulo, V. 10, N 1: 180-200, 2015. 
revolucionária em um projeto baseado na conscientização, que em Paulo Freire toma conotação eminentemente política, transformando-se numa relação que deve ser superada.

É evidente que a filosofia de Dussel, não pode ser tratada como uma filosofia educacional, muito menos ambiental, haja vista que em seus escritos não prevalece uma intenção pedagógica (embora seja um conceito no escopo de seu pensamento), como também não podemos assinalar que a obra de Paulo Freire tenha no conjunto uma preocupação ambiental. Apontamos que ambos pensadores tematizaram um pensamento filosófico-político que na história da América Latina e na história da educação tiveram expressiva influência nas pedagogias críticas e nos instrumentaliza para refletirmos criticamente a sociedade, bem como o contraponto à efetivação dos projetos societários vigentes que excluem o ser humano da possibilidade de vir-à-ser mais (ZITKOSKI, 2007).

Em Dussel, constatamos a preocupação fundamental com a libertação dos sujeitos envolvido no processo de opressão do sistema colonial europeu, cujo processo deixou chagas sociais em nosso continente. Desse modo, o autor nos propõe refletir sobre a nossa condição de sujeitos inseridos na realidade social, para que possamos desenvolver uma perspectiva crítica dos acontecimentos sociais, políticos, culturais e econômicos em torno do sistema vigente. A abordagem latino-americana de Enrique Dussel descobre sua vitalidade e alcance crítico neste esforço de diálogo e aproximação com a proposta de Paulo Freire. Assim, nesta perspectiva somos capazes de descobrir um aspecto fundamental: a existência de muitos mundos diferentes dentro do nosso mundo: a "outridade latino-americana" (DUSSEL, 1986), dentro da nossa realidade. Metodologicamente optamos por valorizar o foco de análise na educação trazendo o enfoque da filosofia e da educação libertadora, por reconhecermos a importância que ela ocupa, enquanto práxis, orientação e efetividade histórica em nosso continente (COSTA, 2011).

A Filosofia da Libertação de Enrique Dussel se apresenta num propósito único: libertar filosófico-politicamente (DUSSEL, 1986). Ou seja, quer libertar-nos politicamente, mostrando-nos alguns mecanismos de dominação e exploração que normalmente nos passam despercebidos ao cotidiano. A libertação filosófica e a libertação política se completam e são inseparáveis no método dusseliano, pois contemplam todas as dimensões da vida pessoal e coletiva. Assim, possibilitam-nos instrumentos teórico-práxicos para libertação integral, não só como sujeitos, mas enquanto sociedade, impelindo-nos a uma nova ordem social justa e igualitária. Consequentemente, 0 apelo à "responsabilidade do outro" e "pelo próximo", que este rosto (Outro) traz está concretamente, existencialmente e historicamente marcado. O "outro", de quem assinala Dussel, é o outro com um rosto, o outro concreto, em milhões de rostos que carregam as marcas do sangue, os sulcos da fome e da humilhação. Esta crítica, o autor não faz no nível das argumentações metafísicas, mas sim no plano humano das opressões historicamente estabelecidas. Em outras palavras, poderíamos falar numa ética da libertação 
como fundamentação ética e radical para a realização humana (DUSSEL, 1986). O "outro" negado de Dussel é, nesse contexto, o oprimido que assinala Freire, uma vez que, o mesmo sempre buscou uma práxis dentro de seu país, sendo incontestável que o "oprimido" (que mencionava em seus escritos) significa o encobrimento de todos os povos da América Latina ${ }^{5}$ (DUSSEL, 1993). A devida e necessária aproximação entre exclusão latino-americana e reconhecimento da solidariedade humana como ponto de partida para uma redefinição do atual projeto societário, requer em ancorar neste método de abordagem na realidade visando transformá-la radicalmente. Tal abordagem envolve compreensões da questão ambiental fruto de sistema colonizador e dominante que por séculos alija o povo latino-americano de sua condição e realização (ASSMANN; SUNG, 2000).

\section{Conclusões}

À luz do que foi explicitado, indicamos que a relevância dos referenciais e categorias trabalhadas por Dussel e Freire possui muitas complementaridades e convergências para a Educação Ambiental crítica, uma vez que, suas compreensões de homem-mundo são vitais para a posição epistemológica assumida por esta. Para a perspectiva crítica em que ambos se inserem, a práxis de dominação não reconhece a alteridade. O outro deixa de ser importante para tornar-se coisa. O agir da opressão, ao negar o Outro como outro, incorpora-o num sistema que o aliena e a possibilidade em transformarmos as formas como nos relacionamos com a natureza, o que implica, nos relacionarmos com a humanidade. Seguindo o viés marxista, para Dussel a práxis de dominação na organização da produção é o que define o grau de alienação na formação social. "No modo de produção assim constituído, o Outro (trabalhador) perde sua liberdade. Sua vida e seu fazer já não lhe pertencem e passa a ser instrumento a serviço de interesses alheios. Alienação e dominação são aspectos intrínsecos à totalidade totalizada" (BOUFLEUER, 1991, p. 68). O processo de libertação tem seu ponto chave na escuta da voz do Outro, o que vem a exigir respeito e responsabilidade para com ele. Segundo Dussel, a libertação que implica num trabalho em favor do Outro, não pode ser resumido na relação homem-homem (práxis), mas inclui a relação homem-natureza (poiesis). "Não há libertação sem economia e tecnologia humanizada, e sem partir de uma formação social histórica" (DUSSEL, 1977, p.69). Logo, o sentido da práxis de libertação será de

\footnotetext{
${ }^{5} \mathrm{Na}$ crítica histórica de Zanotelli, há o seguinte questionamento: Quais são estes traços identitários? Somos latino-americanos? Se o somos, não aceitamos facilmente que o sejamos segundo a visão preconceituosa que os países do Primeiro Mundo têm de nós. Mas o fato de sermos tratados preconceituosamente, estigmatizados como indolentes, preguiçosos, andarilhos, improvisadores, não muito sérios em cumprir os compromissos empenhados, etc... de não termos nem espaço, voz e vez nos meios de comunicação daqueles países, o fato ainda de sermos esquecidos e negados, mesmo e especialmente nos fatos em que somos lembrados (carnaval, futebol e escândalos) essa contraposição, essa discriminação, é também um lugar de nossa identificação. É preciso recolher com cuidado os vetores de nossa identidade e o processo de nossa identificação. ZANOTELLI, J. América Latina: raízes sócio-político-culturais, p. 14.
}

Revbea, São Paulo, V. 10, N 1: 180-200, 2015. 
transposição do horizonte do sistema para construir uma formação social nova e mais justa. "Uma práxis que se restringisse a um movimento intrassistêmico não conseguiria criar algo de realmente novo, pois não passaria de uma mediação dentro de um mundo já dado, dentro de uma ordem marcada pela dominação" (BOUFLEUER, 1991, p.72).

Por tudo isso, a libertação social e política estão dialeticamente relacionadas, sendo compreendidas no processo de vir-à-ser superado na contradição opressor-oprimido/colonizador-colonizado. Nesse âmbito, a Pedagogia do oprimido de Freire colabora por ser uma pedagogia do ser humano nas mais diversas e complexas relações. Ou seja, o educador tem de agir na práxis, e para tal precisa ser educado/educar/educar-se, não the sendo suficiente o simples contato distanciado com aqueles aos quais se destina sua tarefa. E é nesse horizonte que o pensamento de Paulo Freire e Enrique Dussel possuem reconhecimento em suas premissas políticas que se tornam essenciais para a educação ambiental. Por tudo isto,

Educação Ambiental é dimensão da educação, é atividade intencional da prática social, que imprime ao desenvolvimento individual um caráter social em sua relação com a natureza e com os outros seres humanos, com o objetivo de potencializar essa atividade humana, tornando-a mais plena de prática social e de ética ambiental. Essa atividade exige sistematização através de metodologia que organize os processos de transmissão/apropriação crítica de conhecimentos, atitudes e valores políticos, sociais e históricos. Assim, se a educação é mediadora na atividade humana, articulando teoria e prática, a Educação Ambiental é mediadora da apropriação, pelos sujeitos, das qualidades e capacidades necessárias à ação transformadora responsável diante do ambiente em que vivem. Podemos dizer que a gênese do processo educativo ambiental é o movimento de fazer-se plenamente humano pela apropriação/transmissão crítica e transformadora da totalidade histórica e concreta da vida dos homens no ambiente (TOZONI-REIS, 2004, p.147).

A Pedagogia Histórico-Crítica de Saviani traz entre suas contribuições, a necessidade da Educação Ambientalresgatar a importância dos conteúdos curriculares compreendidos de forma reflexiva e crítica no processo educativo (TOZONI-REIS et alli, 2013). Assim, a Educação Ambiental que podemos chamar de histórico-crítica problematiza sua inserção voltada para o processo de formação plena de indivíduos singulares que, ao se apropriarem criticamente dos elementos da cultura, em especial no que diz respeito as relações das sociedades com o ambiente em que vivem, tendo condições objetivas de formarem-se para uma prática social transformadora. Sob o viés da Pedagogia histórico-crítica a Educação Ambiental crítica e transformadora se interessa em identificar quais elementos culturais precisam ser assimilados pelos indivíduos para garantirmos esse processo de humanização descobrindo de que maneira a atividade educativa alcançará esse objetivo (SAVIANI, 1987). 
Em síntese, compreendemos que as posições de Dermeval Saviani, Enrique Dussel e Paulo Freire contribuem com a Educação Ambiental crítica na forma de repensarmos os fundamentos e a práxis educativa ambiental compatíveis com o enfrentamento da desigualdade social da América Latina e o compromisso social manifestado no processo pedagógico emancipatório. Por fim, com estes autores críticos, aprendemos que "a consciência ético-crítica é necessária para que se compreendam as causas da opressão e da exclusão sociais para intervir e transformar as realidades educacional e social" (OLIVEIRA e DIAS, 2012, p. 105).

\section{Referências}

ANDREOLA, B. Ética e solidariedade planetária. In: DALLA VECHIA, A. (Org.). Ética: diversidade e diálogo na produção de referências para a educação. Pelotas: Seiva, 2003, p. 17-37.

ANDREOLA, B. Freire e Habermas: aproximações possíveis e convergências impossíveis. s/d.

ASSMANN, H.; SUNG, J.M. Competência e sensibilidade solidária. Petrópolis: Vozes, 2000.

BOUFLEUER, P. Pedagogia latino-americana: Freire e Dussel. ljuí: UNIJUÍ, 1991.

CASTRO, J. Subdesenvolvimento: causa primeira da poluição. In: CASTRO, J. Fome: um tema proibido. Rio de Janeiro: Civilização Brasileira, 2003.

DUSSEL, E. 20 teses de política. Buenos Aires: CLACSO; São Paulo: Expressão Popular, 2007.

DUSSEL, E. Ética da Libertação na idade da globalização e da exclusão. Petrópolis: Vozes, 2000.

DUSSEL, E. Método para uma Filosofia da Libertação. São Paulo: Loyola, 1986.

DUSSEL, E. Filosofia da Libertação. São Paulo: Loyola, 1977.

DUSSEL, E. 1492: o encobrimento do Outro: a origem do mito da modernidade: Conferências de Frankfurt. Petrópolis: Vozes, 1993.

DUSSEL, E. Filosofia da Libertação: crítica à ideologia da exclusão. São Paulo: Paulus, 1995.

FANON, F. Os condenados da Terra. Rio de Janeiro: Civilização Brasileira, 1979.

FREIRE, P. Pedagogia do Oprimido. Rio de Janeiro: Paz e Terra, 1983.

FREIRE, P. Pedagogia da Esperança. Rio de Janeiro: Paz e Terra, 1994.

FREIRE, P. A sombra desta mangueira. São Paulo: Olho d'água, 1995. 
FREIRE, P; FAUNDEZ, A. Por uma pedagogia da pergunta. Rio de Janeiro: Paz e Terra, 1995.

GHIGGI, G; KAVAYA, M. Frantz Fanon e a pedagogia da "colaboração muscular". In: STRECK, D. (Org.). Pedagogia Latino-americana. Belo Horizonte: Autêntica, 2010. p. 377-391.

HARVEY, D. Justice, nature and the geography of difference. USA: Blackwell Publishers, 1996.

LOUREIRO, C.F.; TREIN, E.; TOZONI-REIS, M.F.; NOVICKI, V. Contribuições da teoria marxista para a Educação Ambiental crítica. Cad. Campinas, CEDES, vol.29, n.77, Jan./Abr. 2009. p. 81-97.

LOUREIRO, C.F. Trajetória e fundamentos da Educação Ambiental. São Paulo Cortez, 2012.

LOUREIRO, C.F. Educação AmbientalTransformadora. In: LAYRARGUES, P. (Coord.). Identidades da Educação Ambiental brasileira. Brasília: Ministério do meio Ambiente: 2004. p. 65-84.

LOUREIRO, C.F. Educação Ambiental e "Teorias críticas". In: GUIMARÃES, M (Org.). Caminhos da educação ambiental. Campinas: Papirus, 2006. p. 5186.

LOUREIRO, C.F.; TREIN, E.; TOZONI-REIS, M.F.; NOVICKI, V. Contribuições da teoria marxista para a Educação Ambiental crítica. Cad. Campinas, CEDES, vol.29, n.77, Jan./Abr. 2009. p. 81-97.

LUKÁCS, G. Ontologia do Ser Social: os princípios ontológicos fundamentais de Marx. São Paulo: Editora Ciências Humanas, 1979.

OLIVEIRA, D. O método da Filosofia da Libertação, segundo Enrique Dussel. s/d.

PORTO-GONÇALVES, C.W. A Ecologia política na América Latina: reapropriação social da natureza e reinvenção dos territórios. Santa Catarina, Interthesis, v. 9, n.1, 2012, p. 16-50.

OLIVEIRA, I; DIAS, A. Ética da libertação de Enrique Dussel: caminho de superação do irracionalismo moderno e da exclusão social. Caxias do Sul, Conjectura, v. 17, n. 3, p. 90-106, set./dez. 2012.

PERALTA, J; RUIZ, J. Educação popular ambiental. Para uma pedagogia da apropriação do ambiente. In: LEFF, E. (Coord.). A complexidade ambiental. São Paulo: Cortez, 2004. p. 241-280.

PORTO-GONÇALVES, C.W. A Ecologia política na América Latina: reapropriação social da natureza e reinvenção dos territórios. Inter. Interdisc. INTERthesis, Florianópolis, v.9, n.1, p.16-50, Jan./Jul. 2012.

SAVIANI, D. Escola e democracia. São Paulo: Cortez/Autores Associados, 1987. 
SAVIANI, D. Saber Escolar, currículo e didática: problemas da unidade conteúdo/método no processo pedagógico. 6 ed. Campinas: Autores Associados, 2010.

SAVIANI, D. A Pedagogia histórico-critico: primeiras aproximações. Campinas: Autores associados, 2005a.

SAVIANI, D. Do senso comum à consciência filosófica. São Paulo: Cortez/Autores associados, 1991.

STRECK, D. (Org.). Pedagogia latino-americana. Belo Horizonte: Autêntica, 2010.

STRECK, D. Paulo Freire e a consolidação do pensamento pedagógico na América Latina. In: STRECK, D. (Org.). Pedagogia Latino-americana. Belo Horizonte: Autêntica, 2010. p. 329-345.

STRECK, D; ADAMS, T; MORETTI, C. Pensamento pedagógico em nossa América: uma introdução. In: STRECK, D. (Org.). Pedagogia Latinoamericana. Belo Horizonte: Autêntica, 2010. p. 19-35.

TOZONI-REIS, M. Educação ambiental: natureza, razão e história. Campinas, São Paulo: Autores Associados, 2004.

TOZONI-REIS, M. Temas ambientais como "temas geradores": contribuições para uma metodologia ambiental, crítica, transformadora e emancipatória. Educar, Curitiba, n. 27, 2006. p. 93-110.

TOZONI-REIS, M.F.C. ; SPAZZIANI, M.L.; TALAMONI, J.L.B; MORALES, A.G.; MAIA, J.S.S; MUNHOZ, R.H; FOSSALUZA, A.S.; GONCALVES, C.E.; SOUZA, D.C.; MENDES, C.B; PINTO, V.S. ; NEVES, J.P.; CRUZ, L.G.; TEIXEIRA, L.A.; CASSINI, L.F.; AGUDO, M.M.; FESTOZO, M.B.; FIGUEIREDO, P.B. ; FRANZI, S. Conteúdos curriculares da Educação Ambiental na escola: contribuições da pedagogia histórico-crítica. In: VII Encontro de Pesquisa em Educação Ambiental- EPEA, 2013, Rio Claro - SP. Anais do VII EPEA, 2013a. p. 1-14

TOZONI-REIS, M. et al. Contribuições do pensamento marxista à Educação Ambiental crítica. In: COSTA, C.A.S.; LOUREIRO, C.F. (Orgs.). A Questão Ambiental: interfaces críticas. Curitiba: Appris, 2013b. p. 65-87.

TOZONI-REIS, M. Contribuições para uma pedagogia criticam na educação ambiental: reflexões teóricas. In: LOUREIRO, C.F.B (Org.). A Questão ambiental no pensamento crítico. Rio de Janeiro: Quartet, 2007. p. 177-221.

TEIXEIRA, L.; TOZONI-REIS, M.; TALAMANI, J. A teoria, a prática, o professor e a educação ambiental: algumas reflexões. Ponta Grossa, Olhar de professor, v. 14, n, 2, 2011, p. 227-237.

ZANOTELLI, J. América Latina: raízes sócio-político-culturais. 3 ed. Pelotas: Educat: 2007.

ZITKOSKI, J. A Pedagogia freireana e suas bases filosóficas. In: GHIGGI, G.; SILVEIRA, F.; PITANO, S. (Orgs.). Leituras de Paulo Freire. Pelotas: Seiva, 2007. p. 229-248. 